\title{
Emotional intelligence, social competencies and cultural adjustment of expatriates in Malaysia: The mediating role of self-motivation.
}

\author{
Jugindar Singh Kartar Singh, Nik Hasnaa Nik Mahmood, Zabedah bt Othman
}

\begin{abstract}
Emotional intelligence and social competencies are a few constructs that predict the cultural adjustment of expatriates. There is a dearth of studies that explored the impact of emotional intelligence and social competencies on the cultural adjustment of expatriates in Malaysia. Hence, this study focusses on the relationship between emotional intelligence and social competencies on cultural adjustment of expatriates. Additionally, the mediation role of self-motivation was examined. This quantitative study used a cross-sectional survey to collect primary data. Random sampling was used to collect data from a sample of 301 expatriates. Questionnaires were sent either by hand or electronically. This study used PLS SEM to estimate the model. The results pointed out that emotional intelligence and social competencies are essential predictors of cultural adjustment. The results also revealed the mediating role of self-motivation. The findings added to the current body of knowledge and presented new insights into the contribution of emotional intelligence and social competencies towards cultural adjustment of expatriates. Based on the findings, organizations and HR managers involved in managing expatriates for global assignment can implement policies and processes to select and prepare the right expatriates for global assignments.
\end{abstract}

Keywords: Emotional intelligence, social competency, selfmotivation, cultural adjustment, expatriates .

\section{INTRODUCTION}

As a result of globalization, more and more organizations are running on global functional models and global mobility plays a key role in solving the labor availability conundrum [1]. As stated in the in the survey by PWC [1], the importance of having the right talent is the most critical factor for business growth. A survey by PWC [1] stated that due to the changes in the global environment, multinationals need to identify, recruit and retain talent globally. The Global Mobility Trends survey by BGRS [2] also stated that the HR function of equipping their MNCs and preparing their expatriates is more critical and challenging nowadays. The report by BRGS [2] further stressed that for sustained competitive advantage, talent mobility has become a key contributor. Palthe [3] added that multinationals depend on expatriates for sustaining competitive advantage and they need expatriates to manage the complexity. Therefore, as stated by Dowling, Festing and Engle [4], a critical success factor for MNCs is having the right people to manage and

Revised Manuscript Received on April 19, 2019.

Jugindar Singh, School of Management, Asia Pacific University of Technology and Innovation

Nik Hasnaa Nik Mahmood, Fakulti Teknologi \& Informatik Razak, Universiti Teknologi Malaysia, Kuala Lumpur, Malaysia

Zabedah bt Othman, Business School, Open University Malaysia Kuala Lumpur, Malaysia operate international operations. However, having access and effectively managing talent globally continues to be a challenge for MNCs.

The number of expatriates going on global assignments is increasing and the data from PWC [1] revealed that number of expatriates on global assignments have increased by $25 \%$ and a further $50 \%$ growth is predicted in assignments by 2020. This will further increase the challenge placed on MNCs and HR managers. This will also lead to an increase in the need for expeditious knowledge transfer [1]. Furthermore, as stated in the Global Mobility Trends survey by BGRS [2], only $54 \%$ respondents reported that they have enough internationally experienced employees and another $20 \%$ stated that they are unsure. Furthermore, around $80 \%$ of companies do not formally assess the adaptability of global assignees. Hence, there is a possibility of failure that can result in business disruption and additional expenses. A total of $55 \%$ of the respondents to a survey by KPMG [5], stated that up to $\% 55 \%$ of the respondents stated that up to $5 \%$ of global expatriates failed where they returned before completing the assignment. Failure in global assignments is both very costly and risky [6]. This issue was supported by a PWC Global CEO Survey, which reported that talent management is given high priority by global organizations [1]. A survey by PWC [7] stated that the cost to send expatriates on global assignments is substantial. It was estimated that a global assignment cost US\$311,000 p.a. The survey also stated that the premature termination of global assignment is $4 \%$. Therefore, organizations need to implement policies and processes to mitigate the causes of failure.

In the economic development of Malaysia, the Information and Communications Technology (ICT) sector plays a crucial role. The performance results of MSC Malaysia for the year 2016 showed that Malaysia recorded RM16.3 billion new investments with RM47.1 billion revenue generated [8]. There are an estimated 355,119 employees engaged in the digital industry in 2017 and around $12 \%$ of current talents in digital industry are nonMalaysians [9]. Frost and Sullivan [9] research revealed that talent requirement in the ICT sector will reach over 540,000 jobs by 2020 . Due to limited availability of skills locally, organizations are hiring expatriates. In addition, the hiring cost and attrition rates were other reasons that the respondents stated for hiring expatiates [9]. Therefore, is 
worth doing a study to find out the successful adjustment of global assignees in the ICTs sector in Malaysia. Moreover, Malaysia's ICT push has shown tremendous growth and the Malaysian government has taken steps to further push the growth of ICT to shape the country's future [10].

Failure to adjust in the home country is one of the causes of failure. Around $41 \%$ of respondents to Mercer's Worldwide survey [11] cited assignees' difficulty in adjusting to the host nation as a primary reason for assignment failure. Furthermore, as reported by Global Mobility Trends survey by BGRS [2], over a quarter (26\%) of the assignees going abroad do not and $18 \%$ experience difficulties in adjusting in the foreign country. One of the major determinants of success is cultural adjustment and the consequence of failure to adjust or inadequate adjustment will be lower level of job performance by the assignees. [12] - [13]. To improve cultural adjustment, researchers have found several predictors that contribute towards the cultural adjustment and performance of expatriates (e.g., [12]- [14] Expatriates face uncertainties in the host country and research has shown that expatriates with high emotional intelligence are able to manage emotions and can adjust better [15]. Based on past studies, social interaction and relationships during global assignments are important factors that facilitate cultural adjustment in the host country [16]. The role of motivation of an expatriate relating to cross-cultural encounters is also a largely overlooked aspect of adjustment [17].

However, there is a dearth of studies on the effect of emotional intelligence and social competencies towards cultural adjustment and the mediating role of self-motivation between the predictors and the dependent variable. There is also a paucity of research on the cultural adjustment of global assignees currently working in the ICT sector in Malaysia. In addition, researchers have generally focused on specific issues such as past international experience [12], cultural sensitivity [14], and family adjustment [18]. This is a more holistic study to examine whether emotional intelligence and social competencies can lead to successful cultural adjustment and the mediating role of self-motivation between the two. A clear understanding of the impact of social competencies and emotional intelligence would aid organizations to design their expatriates' selection, talent management and support practices to address the challenges and failure of expatriates and sustain competitive advantage.

\section{LITERATURE REVIEW}

\section{The conceptualization of Cultural adjustment}

The conceptions of expatriate adjustment over time were conceived for the last decades as following a U-shaped curve [19]. The interest in cultural shock and adjustment was triggered by the Theory of Adjustment [20]. Based on this theory, an expatriate going to a host country will take some time to adjust and this will affect his or her performance. The study on culture shock is consistently used to understand cultural adjustment (e.g., Bhaskar et al. [21]). According to Hofstede [21], cultural adjustment is referred to as putting individuals under stress due to the forced exposure to a different cultural environment. The famous Framework for International Adjustment by Black et al. [22] is frequently referred to by research such Bhaskar et al. [21]) and it describes the cross-cultural adjustment process for global assignees. The proposed model by Black et al. [22] is a multifaceted conceptualization of adjustment [12]. Several studies have attempted to define and explain the degree of cultural adjustment [12] - [4]. Cultural adjustment was defined generally as the psychological discomfort that was categorized as a three-dimensional phenomenon that encompasses interaction, work, and general adjustment [23]. Haselberger et al. [24] stated that adjustment is an individual-environment relationship that encompasses the dimensions of behaviors, feelings and cognitions. Haselberger et al. [24] further distinguished between cognitive, affective and behavioral dimensions. Constantine et al. [25] defined cultural adjustment as a process of understanding and incorporating values, beliefs and behaviors of the host country culture in the perspective of the person's home country culture. Therefore, there are several definitions of cultural adjustment and generally most definitions refer to the process of adjustment to living and working in another country and culture.

Past studies have identified several constructs that influenced cultural adjustment of expatriates [22] - [12]. A study by Opkara [26] identified that previous experience, cross-cultural training and socialization influenced cultural adjustment of expatriates. Several researchers have stated that the spouse and family support are important for cultural adjustment of expatriates (e.g., Rosenbusch and Cseh [20]). However, a study by Davies et al. [27] found the expatriate adjustment is mainly due to an interaction effect of partner nationality and length of stay. The study found that expatriates with partners from the host country perceived a much higher increase in cross-cultural adjustment compared to expatriates with home country partners. Another study that was based on the social identity theory, found that host country language proficiency of the expatriate had multifaceted effects on his/her network-related work and non-work adjustment [28]. A recent study by Salgado and Bestida [29] revealed that for successful cultural adjustment, expatriates need organizational support, language skills and social skills. Harari et al. [30] studied personality traits as antecedents of expatriate adjustment. The study revealed that personality is one of the factors that contributed $20 \%$ of the variance in expatriate adjustment. In the study by Harari et al. [30], cultural adjustment was influenced by the individual's emotional stability and openness. Wechtler et al. [31] found that age facilitates regulation of emotions on general living adjustment and interactional adjustment. Therefore, it was noted that cultural adjustment is influenced by a number of personal characteristics, job factors and other non-work related factors.

The impact of Emotional competencies towards cultural adjustment of expatriates.

As explained by Cherniss et al. [32], emotional intelligence (EI) is an individual's ability to perceive, use, understand, and manage emotions. Mayers, Roberts and 
Barsade [33] further stated that an individual with high emotional intelligence has higher ability to do better reasoning about emotions and enhance thought through his/her ability to use emotions. Emotional intelligence was referred to by Goleman [34] as a wide array of competencies and skills that drive performance. Goleman [34] stated that emotional intelligence includes five dimensions namely selfawareness, self-regulation, motivation, empathy, and social skills. According to Bar-On [35], an individual with higher emotional intelligence can understand and relate well with other people. Higher levels of emotional intelligence enable an individual to cope well with pressures, challenges and other demands [35]. According to Cherniss et al. [32], the 'trait' approach is one of the perspectives of looking at EI. Mayer et al. [36] further added that EI refers to abilities of individuals that accounts for how people vary in their emotional reports. Higher understanding of emotions by individuals results in better problem solving and be concluded that the focus of EI is on the ability of a person to recognize own and others' emotions, differentiate the feelings and act in a manner to achieve goals.

Researchers and scholars have asserted that EI contributes positively towards job performance and other [34] revealed that EI is more effective than technical skills and cognitive ability. In the study by Stein and Bok [37], the correlation that was attributable to EI ranged up to .45 . had a positive influence on their job performances. Palmer et al. [38] tested that relationship between EI and effective component of effective leadership. Several researchers found evidence to support the positive role of EI towards job performance. (e.g., Stein and Bok, [37]; Palmer et al. [38]). However, some researchers have argued that usefulness of EI. Co^te' \& Miners [39] argued that EI and cognitive intelligence are related yet distinct constructs. The study by Co`te' \& Miners [39] found that the association between EI and task performance will become more positive as cognitive intelligence decreases. In addition, the interactive effect of cognitive intelligence makes emotional intelligence is an important predictor of task performance. In a study by Cote [40], emotional intelligence showed only low correlations with several work criteria. Cote [40] further suggested that to better understand how EI relates to work criteria, the contextual and dispositional variables need to be considered. Zeidner et al. [41] questioned importance of EI and asserted that EI does not ensure that employees will practice competent behaviors in the workplace. Petrides and Furnham [42] further stated that EI is not a form of intelligence. They argued that EI is just a moral quality of individuals.

The influence of EI on an expatriate's cultural adjustment has received attention by several researchers. A study by Peltokorpi [43] revealed that emotional stability was one of the constructs that had a positive influence on general living and interaction adjustment. Another study by Moon [44] showed that social awareness and relationship management dimensions of EI explained cultural intelligence. The results of this study showed that only that performance. Based on the several definitions' of EI, it can human resource outcomes [34] - [37]. A study by Goleman Studies have found that higher levels of EI of employees leadership and found that EI may be an important

two dimensions of EI are related to specific factors of cultural intelligence. A study by Gabel et al. [45] found a positive relationship of EI and cultural adjustment. However, the cultural adjustment was not correlated with any EI dimension. This shows that maladjustment can result in intention to terminate the assignment early [45]. A study by Koveshnikov et al. [46] found that the work related, general living and interactional adjustment of global assignees had a positive relationship with EI. The study also highlighted that cultural similarity only influences general living adjustment and not interactional or work adjustments. Wechtler [31] also stated that age facilitates and regulates the utilizations of emotions on general living adjustment. Therefore, the influence of EI is effected by the type of cultural adjustment and age differences. In this study, it was hypothesized that:

H1: Emotional intelligence is related to cultural adjustment of expatriates.

The relationship between social competencies and cultural adjustment

Scholars and researchers have identified several components of social competence based on various criteria. In todays globalized environment, social skills are becoming more critical because such skills allow employees to communicate and interact to understand and be understood by each other [47]. Competencies refer to the abilities and skills to do something more efficiently. Higher levels of social skills lead to more effective job outcomes such as productivity [47]. Social competencies can facilitate better interactions because and individual can utilize such skills or competence to recruit and maintain supportive relationships with others [48]. Social competence of an individual covers interpersonal, personal and intercultural competence that facilitates individuals to participate in more effective work related outcomes [49]. Through higher levels of social competence, individuals are able to coordinate their adaptive responses flexibly and organize their social behavior in different social situations [50]. Kostelnik et al [51] definition of social competence includes several components namely decision making and planning, development of cultural competence, acquiring inter-personal skills, adoption of social values and learning how to regulate personal behavior. Therefore, social competence encompasses several skills that facilitate effective human interactions that facilitate butter outcomes.

Expatriate job assignments are sometimes stressful due to uncertainties and require adaptation to multiple environments. Based on previous research, higher social competencies that encompasses relational skills and communication ability were found to be predictors of cultural adjustment and performance of expatriates (e.g., Bhaskar et al., [12]; Hechanova et al. [52]). Researchers have stated that the development of relationships is a key variable of effective cultural adjustment and intercultural job performance [53] - [12]. Bhasker et al. [12] stated that relational skills are positively related cultural adjustment of expatriates. Cultural adjustment subsequently adjustment 
affects the performance of expatriates. Abe and Wiseman [54] stated that one of the important social competency was communication ability. Wang et al. [55] found that for expatriates working in Europe and Australia, communication skills were important. However, the study revealed that due to cultural differences and perceptions about work-life balance, the expatriates' communication skills were not easily transferable to the host country. Researchers have proposed it would be easier for expatriates to interact with host country nationals through acquisition of better relational skills [56]. Social competence can be related to social networking and social capital. To improve the success of expatriate cultural adjustment, social capital is an important factor [57]. The study found that the network characteristics of expatriates had a positive relationship with expatriate psychological well-being and adjustment. The study by Lee and Kartika [57] also revealed that social capital is one of the important factors that can enhance expatriate cultural adjustment. Hechanova et al. [52] carried out a study on the antecedents of expatriate adjustment and found interpersonal skills had a positive influence on expatriate general adjustment. In this study, it is hypothesized that:

H2: Social competencies are related to cultural adjustment of expatriates.

\section{The mediating role of Self-Motivation}

There are several theories and definitions related to selfmotivation. The Self Determination Theory proposed by Deci and Ryan [58] posits that intrinsic and extrinsic motivation are the forces that shape who we are and how we behave. The model of intrinsic and extrinsic motivation proposed by Porter and Lawler [59] states that intrinsic motivation is satisfaction derived by employees from an activity they carry out. Unlike intrinsic motivation, extrinsic motivation refers to satisfaction that comes from the extrinsic consequences to which the activity leads [59]. Several past studies have examined the influence of motivation towards cultural adjustment of expatriates (e.g., Haines, Saba, \& Choquette, [60]; Earley and Ang, 17]). Haines, Saba and Choquette [60] found that when expatriates were transferred to another country, their work adjustment was positively influenced by cultural motivation. Motivation was referred to by Earley and Ang [17] as a crucial component because the adaptation of expatriates encompasses both "intelligent" and "motivated" action. It was further stressed by Earley and Ang [17] that either motivation and intelligence was sufficient for the cultural adjustment of expatriates. Ang et al. [61] further argued that higher levels of cross-cultural motivation will lead to stronger attention and energy toward cross-cultural situations. Chen et al. [62] proposed that higher cross cultural motivation of expatriates will lead towards adjustment. In a study involving expatriates in Malaysia by Ramalu, Wei, and Raduan [63], it was found that expatriates with higher level motivational cultural intelligence adjusted well in the domain of general adjustment. Another study identified three motivation factors namely support from the host country, satisfaction with the facets of adjustment and host country family support that were related to general adjustment [64].

There is limited research on the relationship between social competencies and EI towards self-motivation. Bandura and Schunk [65] tested and found that selfmotivation was an effective mechanism for developing competencies. One of the personal capabilities stated by Goleman [34] is motivation. Motivation refers to a passion where employees take an extreme interest to work based on non-monetary rewards. As explained by Goleman [34], the employees persistently purse their goals for reasons that go beyond money or status. Based on this, expatriates can be motivated by a desire to achieve for the sake of achievement [34]. A study by Palmer et al. [38] found that EI was correlated with the inspiration motivation component of transformational leadership. A study by Levitats an VigodaGadot [66] found a positive relationship between EI and employees' motivation and job outcomes. Social skills are another component of emotional intelligence and socially skilled people tend to have knack for finding rapport [34]. According to Goleman [34], social skills are related to motivation because socially skilled people tend to be optimistic and are expert persuaders. Some of the components of social competencies are communication skills, relational skills and language proficiency. A study by Mol et al. [53] found that local language proficiency positively influenced effective interactions and communications and this may further motivate the expatiates on global assignments. Results of a study by Velten, [67] showed that the expatriates communication motivation was positively affected by their competencybased intercultural communication. Therefore, both EI and social competencies are effective predictors of expatriates sent on global assignments.

Past studies has not empirically tested the role of selfmotivation as a mediator between EI and cultural adjustment. Similarly, the mediating role of self-motivation between social competencies and cultural has not been examined. However, past research has shown that selfmotivation has been empirically tested as a mediator between various human resource constructs and practices (e.g., Haines et al. [60]). In a recent study by Evelyne et al. [68], the relationship between job characteristics and performance was mediated by motivation. In a study by Haines et al. [60]), the relationship between cross cultural adjustment and job performance was more likely to be mediated by work adjustment. In another study by Charbonneau [69], transformational leadership was related to performance indirectly, through the mediating effects of intrinsic motivation. In a study by Ramalu et al. [70], it was revealed that relationship between job performance and personality was mediated through interaction and work adjustment. Based on the pattern of relationships and the role of self-motivation as a mediator between numerous human resource outcomes, it is strongly believed that the relationship of EI and social competencies towards cultural adjustment is mediated by self-motivation. Therefore, the following hypothesis were developed for testing in this study: 
H3: Self-motivation mediates the relationship between emotional intelligence and cultural adjustment.

H4: Self-motivation mediates the relationship between social competencies and cultural adjustment.

\section{METHODOLOGY}

\section{Research Design and Conceptual Framework}

Prior to undertaking this study, the research philosophy that refers to the assumptions on developing knowledge was established. This study is based on positivism philosophy and the researcher used existing theory to develop the research hypothesis [71]. This study used a deductive approach and a quantitative method to collect primary data in numerical form from large samples [71]. This was an explanatory study to test the hypothesis of a causal relationship between variables [72]. In this cross sectional study, the collection of primary data was through the distribution of self-administered questionnaires. The data analysis was done through SPSS and Smart-PLS tools. In this inferential approach, the researcher analyzed characteristics or relationships [72].

\section{Population and Sample Size}

The first task was to identify the study population and the sampling frame. The population for this research were expatriates engaged in the ICT sector. Simple random sampling was used as this is a probability sampling where each sample element in the sampling frame that was developed has an equal chance or the same probability of being selected [72]. The researcher prepared a sampling frame of 1130 respondents and a number was allocated for each item. In this survey-type research study, a large sample of 900 sampling elements were identified because the percentage of responses generally is as low as 20 to $30 \%$ [72]. The formula by Krejcie and Morgan [73] was used where the margin of error was $5 \%$ and the confidence level was $95 \%$. The sample size calculated based on a target population of 12,000 expatriates was 384 . This target sample size of 300 for this study complies with the formula provided by Tabachnick and Fidell [74]. According the formula, the sample size $\mathrm{N}=50+8 \mathrm{~m}$ (where $\mathrm{m}=$ the number of independent variables).

\section{Instrumentation}

The questionnaire consisted of two parts with closed ended questions. The first part of the questionnaire was to collect and thereafter describe the demographical profile of the respondents. The next part was the attitude and behavioral type structured questionnaires where the researcher used a five point Likert-type scale was used. The questions in this study were adapted from past research studies. The Likert five-point-scale questions on cultural adjustment were adapted from studies by Black and Stephens [23] and Searle and Ward [75]. The questions were sent for checking to experts. The questions on emotional intelligence were adapted from the 16-item emotional intelligence scale developed by Wong and Law [76]. The five point Likert scale questions on social competencies were adapted based on studies by Holopainen and Bjo“rkman [77], Liu and Schaffer, [78] and Liu and Lee [79]. The Likert five-point-scale questions for self- motivation were adapted based on studies by Rioux, Bernthal and Wellins [80] and Haines, Saba and Choquette [60]. The questions were sent to experts in this subject matter for checking. Face validity refers to review of the questions by experts and their agreement on the valid measure of the concept [81]. In addition, pilot testing was done to further check validity and understanding of the questionnaire. The questionnaire items were revised upon reviewing the results of the pilot testing.

\section{Data Collection}

Primary data was collected using a survey method that was concerned with analysis of the relationship between the variables [72]. The questionnaire was either sent by hand or e-mailed to respondents identified from the sampling frame. After a lapse of three months, only 225 responses were received. The questionnaires were checked for errors and omissions. Some of the questionnaires were returned for correction. The time period for data collection was extended and attempts were made to appeal to the respondents through phone and e-mail. At the end of the fourth month, 318 questionnaires were received. The number of questionnaires received through mail were 247. Another 71 questionnaires were received by hand through direct distribute and collect method. The questionnaires were checked and only 301 questionnaires were good.

\section{Data Analyses}

For data analysis, SPSS version 19 and Smart-PLS Version 2 was used. Descriptive statistics were obtained by using SPSS Ver19 tool. A two-step process for PLS-SEM assessment involved assessment of the measurement and structural model [82]. In the first step, the outer model was examined and the reliability and validity of data was confirmed. In the second step, the structural model was examined to identify the path coefficients and significance. To assess the structural model in PLSSEM, three key criteria posited by Hair et al. [83] were used. The key assessments include coefficient of determination, the effect size, and significance of the path coefficients. The researcher used bootstrapping which uses multiple resamples from the data. In this study, the researcher used 1000 bootstrap samples [82].

\section{RESULTS}

\section{Demographic profiles of the respondents}

Majority of the respondents were males (71\%). There were 87 females. Most of the respondents were married $(57 \%)$. In the age range, most of the respondent were between the age range of 26 to 30 years old $(41 \%)$. Another $29 \%$ were in the age range of 31 to 35 years. The high number of young expatriates could be due to their willingness to travel. Based on the length of stay in Malaysia, most of the respondents (34\%) stayed for more than 1 year. Next came respondents $(n=78)$ who stayed between 1 to 2 years. The minimum length of stay was 6 months. 
International Conference on Recents Advancements in Engineering and Technology (ICRAET-18) |15th and 16th March 2019|Siddhartha Institute of Technology \& Sciences, Telangana, India.

\section{Normality and Multicollinearity}

To measure the distribution and normality, the researcher included Skewness and Kurtosis. The skewness values of all constructs were between the ranges of -.638 to -.006 This indicates the scores are closer to zero and below the cut-off point of 1 [83]. The kurtosis values between -.0.543 to 0.571 are close to zero and this indicates normality of data [83]. There is low degree of correlation between independent variables. The tolerance value should be more than .10 and the VIF value should not exceed 10 [83]. The value of tolerance as shown in Table 2 is not less than .10. The VIF values fall below the cut-off of 10 . This confirmed that based on the data shown in Table 2, multicollinearity was not violated in this study.

\section{Descriptive statistics of variables}

The researcher used descriptive statistics to provide a summary of the respondents of this study and measures showing mean and standard deviation of the constructs. Table 3 shows that all the independent variables have a mean score of around 4 . This shows that all the constructs in this study were rated highly by the respondents

Table1: Measure of Skewedness, and Kurtosis

\begin{tabular}{|c|c|c|c|c|}
\hline \multirow[t]{2}{*}{ Variable } & \multicolumn{2}{|c|}{ Skewness } & \multicolumn{2}{|c|}{ Kurtosis } \\
\hline & $\begin{array}{r}\text { Stati } \\
\text { stic }\end{array}$ & $\begin{array}{l}\text { Std. } \\
\text { Error }\end{array}$ & $\begin{array}{r}\text { Stati } \\
\text { stic }\end{array}$ & $\begin{array}{l}\text { Std. } \\
\text { Error }\end{array}$ \\
\hline Emotional & -.282 & $0^{.14}$ & .453 & .280 \\
\hline Social & -.006 & $0^{.14}$ & -.545 & .280 \\
\hline $\begin{array}{c}\text { Self- } \\
\text { Motivation }\end{array}$ & -.638 & $0^{.14}$ & .571 & .280 \\
\hline Cultural Adj. & -.374 & $0^{.14}$ & -.003 & .280 \\
\hline
\end{tabular}

Table 2: Measure of multicollinearity

\begin{tabular}{|l|l|l|}
\hline \multirow{2}{*}{ Variable } & Tolerance & VIF \\
\cline { 2 - 3 } & & 2.758 \\
\hline Emotional & .363 & 2.758 \\
\hline Social & .332 & 3.106 \\
\hline $\begin{array}{c}\text { Self- } \\
\text { Motivation }\end{array}$ & .381 & 1.692 \\
\hline
\end{tabular}

Table 3: Mean and Standard Deviation of variables

\begin{tabular}{|l|c|c|c|c|}
\hline Variable & $\begin{array}{c}\text { Emotio } \\
\text { nal }\end{array}$ & Social & $\begin{array}{c}\text { Self } \\
\text { Motivati } \\
\text { on }\end{array}$ & $\begin{array}{c}\text { Culture } \\
\text { Adj. }\end{array}$ \\
\hline Mean & 4.110 & 4.090 & 4.202 & 4.184 \\
\hline Std. Deviation & 0.490 & 0.476 & 0.563 & 0.551 \\
\hline
\end{tabular}

Table 4: Construct Validity and Reliability

\begin{tabular}{|l|l|l|l|l|}
\hline & $\begin{array}{l}\text { Cronbach's } \\
\text { Alpha }\end{array}$ & tho_A & $\begin{array}{l}\text { Composite } \\
\text { Reliability }\end{array}$ & AVE \\
\hline Adjustment & 0.928 & 0.93 & 0.939 & 0.608 \\
\hline $\begin{array}{l}\text { Emotional } \\
\text { Intelligence }\end{array}$ & 0.922 & 0.925 & 0.932 & 0.474 \\
\hline $\begin{array}{l}\text { Self-Motivation } \\
\text { Social } \\
\text { Competence }\end{array}$ & 0.912 & 0.916 & 0.925 & 0.530 \\
\hline
\end{tabular}

\section{Reliability}

To achieve consistent results, the researcher tested for reliability [72]. The researcher used Cronbach's alpha to test reliability. Garson [84], specified that Cronbach alpha value of to .80 of higher was considered a good scale. A value of .70 was considered an acceptable scale. Garson [84] further cautioned that Cronbach's alpha measures tend to underestimate reliability. Hair, Ringle, and Sarstedt [82] recommended that reliability should be higher than 0.70 . The rho values for each construct were above 0.80 and below 0.93. In this research, reliability was confirmed because the Cronbach's alpha values were higher than 0.7 for all the constructs (Table 4).

\subsection{Outer loadings}

As stated by Garson [84], loadings shown in the outer model were the focus in model which was classified as a reflective model. The loadings shown in the outer the absolute contribution of the indicator to the definition of its latent variable [84]. The latent variable is considered more reliable if the loadings are closer to 1. 0. Hair, Ringle, and Sarstedt [82] stated that in a good model, the loadings should be above .70. To improve reliability, the indicators with a measurement loading in the .40 to .70 range should be dropped [82]. In this research, three indicators with low loadings were deleted [82]. The loadings are shown in Figure 1 below.

\section{Convergent Validity}

The average variance extracted (AVE) was used by the researcher to test convergent validity. In this reflective model, the AVE reflects the average communality for each latent construct. As stated by Hair, Ringle and Starstedt [82], the AVE should be greater than .5 in a good model. As shown the Table 4, all the AVE values for the indicators were close to 0.5 . This indicated that the convergent validity was good.

\section{Coefficient of Determination $\left(R^{2}\right)$}

The researcher used bootstrapping to assess the path coefficients' significance. In this study, the minimum number of bootstrap samples was 1,000 . The value $\mathrm{R}^{2}$ is explained the variance in the cultural adjustment caused by the independent variables. [84]. As stated by Hair, Ringle, and Sarstedt [82], the $\mathrm{R}^{2}$ level that is classified as high is dependent on the specific research discipline. The $\mathrm{R}^{2}$ values of $0.75,0.50$, or 0.25 for dependent variable and the predictor variables in the structural model can be described as substantial, moderate, or weak, respectively [82]. In this study, the R2 value of 0.545 for the defendant variable is considered moderate. The R2 value of 0.402 for the mediating variable self-motivation was low.

\section{Discriminant Validity}

In this study, the researcher used the AVE to establish discriminant validity. The discriminant validity was based on the Fornell-Larcker criterion [84]. Based on this criteria, for all latent variables, the square root of AVE was greater 
than its correlation with any other latent variable. As shown in Table 5, the top number in any factor column is higher than the numbers below it [84]. Therefore, discriminant validity was within the specified values and the measurement model was successfully validated.

Table 5: Discriminant Validity

\begin{tabular}{|l|l|l|l|l|}
\hline & $\begin{array}{l}\text { Cultural } \\
\text { Adj }\end{array}$ & EI & $\begin{array}{l}\text { Self } \\
\text { Motivation }\end{array}$ & $\begin{array}{l}\text { Social } \\
\text { Competence }\end{array}$ \\
\hline $\begin{array}{l}\text { Cultural } \\
\text { Adjustment }\end{array}$ & 0.779 & & & \\
\hline $\begin{array}{l}\text { Emotional } \\
\text { Intelligence }\end{array}$ & 0.652 & 0.731 & & \\
\hline $\begin{array}{l}\text { Self } \\
\text { Motivation }\end{array}$ & 0.623 & 0.565 & 0.728 & \\
\hline $\begin{array}{l}\text { Social } \\
\text { Competence }\end{array}$ & 0.660 & 0.726 & 0.615 & 0.675 \\
\hline
\end{tabular}

Table 6: Path Coefficients and Hypothesis Testing

\begin{tabular}{|l|c|l|c|c|}
\hline & $\begin{array}{l}\text { Original } \\
\text { Sample }\end{array}$ & $\begin{array}{l}\text { Sample } \\
\text { Mean }\end{array}$ & $\begin{array}{c}\text { T } \\
\text { Statistics }\end{array}$ & $\begin{array}{c}\text { P } \\
\text { Values }\end{array}$ \\
\hline EI > CA & 0.286 & 0.287 & 4.141 & 0 \\
\hline EI > Motivation & 0.234 & 0.237 & 3.056 & 0.002 \\
\hline Motivation-CA & 0.302 & 0.298 & 5.009 & 0 \\
\hline $\begin{array}{l}\text { Social > Cultural } \\
\text { Adjustment }\end{array}$ & 0.258 & 0.26 & 3.582 & 0 \\
\hline $\begin{array}{l}\text { Social > } \\
\text { Motivation }\end{array}$ & 0.438 & 0.441 & 6.226 & 0 \\
\hline
\end{tabular}

\section{Hypothesis testing}

The path coefficients for the inner model are shown in Figure 1 and Table 6. In this research, the standardized path coefficients were checked. The weight for the path coefficients can be between -1 to +1 . The closed the weight to 1 , the stronger the path coefficient. [84]. The path coefficients $(\beta)$, t-value and their significance values are shown in Table 6 . The t-values shown in Table 6 are above 1.96 and this indicates a significant path [83]. For EI and social competences to cultural adjustment, the t-value was significant. The standardized regression value of .29 showed a significant path and positive relationship between emotional intelligence and cultural adjustment $(p<0.05)$. The standardized regression value of .26 showed a significant path and positive relationship between social competencies and cultural adjustment $(\mathrm{p}<0.05)$. Thus, the hypothesis $\mathrm{H} 1$ and $\mathrm{H} 2$ were supported.

Bootstrapping was done and for the mediator testing, the results revealed that both direct paths were statistically significant. The type of mediation here is a called "partial mediation" since the direct effect of emotional intelligence on cultural adjustment was still significant after the mediator variable entered the model even though the path coefficient for EI is reduced to 0.29. Similarly, the direct effect of social competencies on cultural adjustment was still significant after the mediator variable entered the model even though the path coefficient for social competencies is reduced to 0.26 In this case, EI and social competencies both have significant direct effect on cultural adjustment and also significant indirect effect on cultural adjustment through the mediator variable namely self-motivation. Hypothesis $\mathrm{H} 3$ and $\mathrm{H} 4$ were supported because the t-value was above 1.96 for both the indirect path and the p-value was

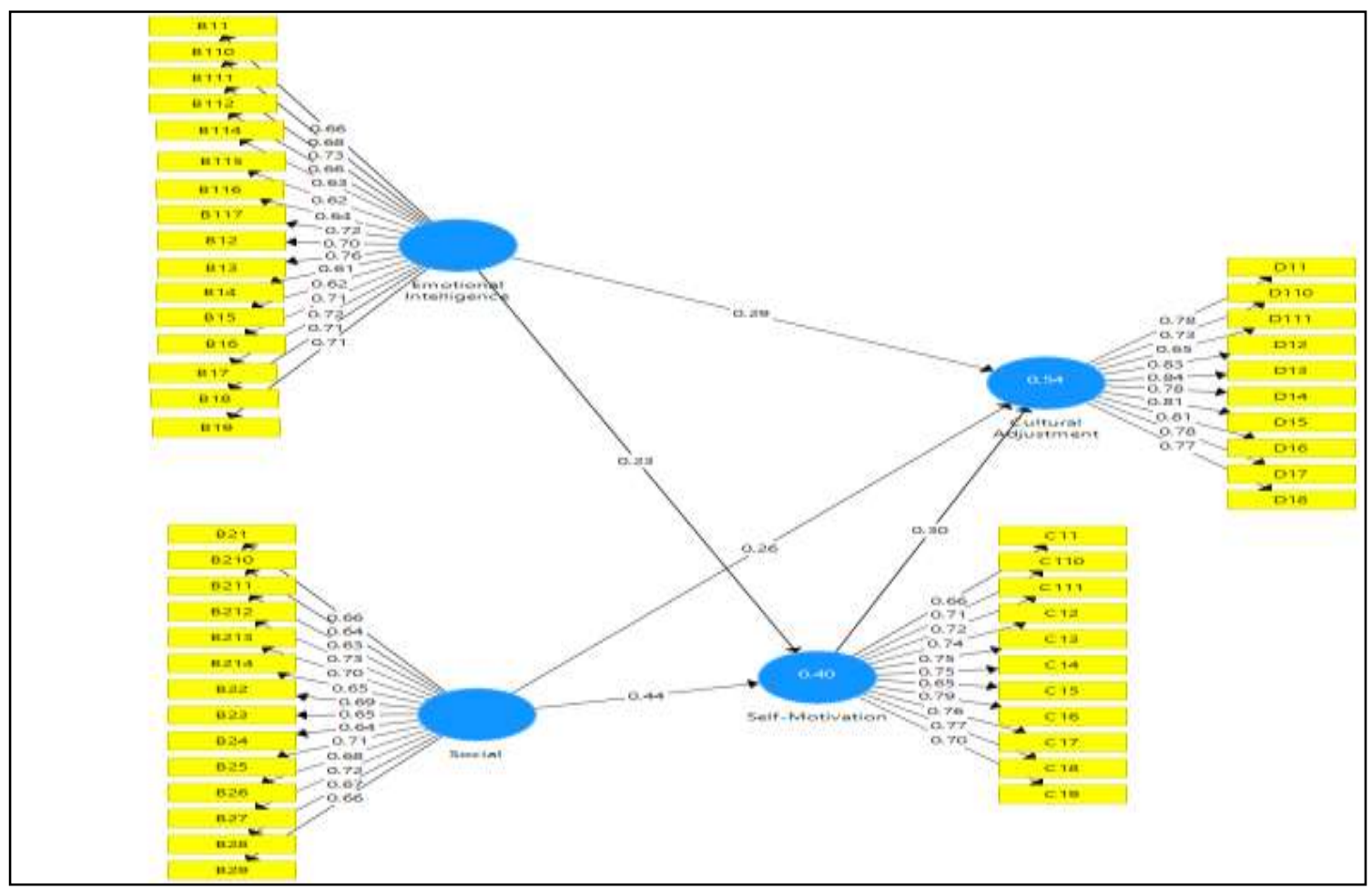

Figure 1: Path Coefficients diagram 


\section{DISCUSSION AND RECOMMENDATION}

The purpose of this research was to find out the impact of emotional intelligence and social competencies on the cultural adjustment of expatriates in Malaysia. In addition, the mediating role of self-motivation between the two constructs was examined. In this study, it was shown that emotional intelligence had a positive influence on the cultural adjustment of expatriates. This study revealed that EI plays a critical role in predicting the cultural adjustment and thereby success expatriates sent on global assignments. In this study, support was found for the propositions made by several researchers who stressed the importance of emotional intelligence in predicting the cultural adjustment of expatriates [44] - [45]. Moon [44] found that social awareness and relationship management dimensions of EI explained cultural intelligence. Similarly, a results of study by Gabel et al. [45] revealed that EI was a positive predictor of cultural adjustment. Studies have also shown that maladjustment can lead to failure in global assignments (e.g. Bhaskar et al. [12]). Thus EI helps to increase the probability of cultural adjustment. Furthermore, this research revealed the critical role of and the findings emphasize the crucial role of EI and social competencies in the cultural adjustment of expatriates engaged in the ICTs sector in Malaysia.

The evidence further revealed the importance of social competencies. Therefore, as revealed in this study, greater level of social competencies will lead to better the cultural adjustment of expatriates. The results of this research did not deviate from past studies that found social competencies as a predictor of cultural adjustment (e.g., Bhaskar et al., [12]; Hechanova et al. [52]). Bhasker et al. [12] stressed the importance of the relational skills that facilitate expatriates to communicate an interact with the nationals in the host country. Therefore, the results of this study provided further support to the claim by other scholars that social competencies and emotional intelligence are crucial predictors of successful cultural adjustment and performance by expatriates.

The findings of this study further revealed that selfmotivation acts as a mediator between emotional intelligence and cultural adjustment. This was one of the few studies that proved the mediating role of self-motivation between the predictors that include emotional intelligence and social skills and the dependent variable that is cultural adjustment of expatriates. Past studies have pointed out that emotional intelligence is related to self-motivation [66]. Scholars have also revealed that social skills are another component of emotional intelligence. Socially skilled people tend to have knack for finding rapport and socially skilled people tend to be optimistic and are expert persuaders [34]. Although past studies have not empirically tested the mediating role of self-motivation between the independent study shows the importance of self-motivation. Expatriates should be willing to go on global assignments in another country and exercise flexibility to adjust in the host country.

This study provided several theoretical, academic and practical implications. This study provided additional theoretical support for the role of emotional intelligence and social competencies as predictors of cultural adjustment of and dependent constructs of this study but the results of this

expatriates' adjustment. From the theoretical perspective, this study further provided support for the role of selfmotivation as a mediator between the independent variables in this study and cultural adjustment factors. This research will add to the existing literature related to cultural adjustment of expatriates and assist to fill the research gaps. This was one of the first study to examine empirically the relationships between expatriate emotional intelligence, social competencies, cultural adjustment and self-motivation of expatriates working in the ICTs sector in Malaysia.

From the practical viewpoint, the results of this study provide additional information for companies in recruiting, developing, motivating and providing support to expatriates. Companies that manage their expatriates successfully should focus on emotional intelligence, self-motivation and social competencies that make the global assignments successful. Companies need to assign global jobs to expatriates whose EI and social competencies are high and further ensure that these skills are matched by their cross cultural adjustment abilities. In addition, the expatriates must be motivated to work overseas. Other forms of motivation should also be included such as career advancement, additional allowances and support for the family. Cultural adjustment is also an important component of expatriates' success. In addition, the success of expatriates includes completion of assignment and job performance. Based on the cultural dimensions specified by Hofstede [21], Malaysia is a collectivist society with high power distance. Therefore, expatriates coming from individualist cultural dimension or cultures with low power, distance, may need to be flexible to adapt and build the networking. Malaysia is also a multi-ethnic country and expatriates need to understand the local culture. This requires higher levels of emotional intelligence and social skills. Therefore, training should be included during the pre-expatriation and post expatriation period of the engagement. Other than training on social skills and emotional intelligence, expatriates should be trained about the Malaysian culture and the training should be tailored based towards the Malaysian culture. In addition, companies should have a rigorous selection process and send the right people for the right reasons to global assignments. This study has revealed that other than technical skills, EI, social competencies and self-motivation should be included in the selection criteria. In addition, companies should send people who are culturally literate and are flexible to adjust in the host country. Hence, expatriates who add most value to their organizations are those who build relationships and willingly experiment with different customs in the host country.

From the academic perspective, the results of this study provided academicians with further understanding of the factors that contribute towards success of expatriates and recommendations for future research by academicians. This study has several limitations and the limitations provided recommendation for future research on this subject matter. Firstly, there are other moderators and mediators such as gender, age of expatriates and marital status that were not 
examined. Future studies should include the categorical variables as moderators. Secondly, this study did not examine the dimensions of emotional intelligence. Similarly, scholars have stated that cultural adjustment is a multidimensional construct rather than a unitary construct and in this study the dimensions of cultural adjustment were not examined. Future studies should examine the dimensions of cultural adjustment and emotional adjustment. This study also did not collect data from expatriates who were not successful or returned prematurely to their home country. For future studies, a more in-depth research on expatriates who were not successful is recommended. Furthermore, this study was in the IT sector only and similar studies in other sectors can yield further evidence and different findings. To get further in-depth understanding of the cultural adjustment and performance of expatriates, it is recommended that a qualitative study of a mixed method study be done in future. The qualitative or available on this subject matter. of.

\section{REFERENCES}

1. PWC. Talent Mobility 2020. The next generation of internationalAssignments. 2010 [cited 15 April 2019]. tomorrows-people/future-of-work

2. BRGS. Breakthrough to the Future of Global Talent Mobility, Global mobility trends survey. 2016 [cited 15 March 20194].

Availablefrom:http://globalmobilitytrends.bgrs.com/asset s2016/downloads/Key-

3. Palthe J. The relative importance of antecedents to crosscultural adjustment: Implications for managing a global workforce. International Journal of Intercultural Relations. 2004 Feb 1;28(1):37-59.

4. Dowling PJ, Festing M. Engle AD. International Human Resource Mgmt. London: Cengage; 2008

5. KPMG. Global Assignment Policies and Practices Survey. 2012 [cited 15 April 2019]. Available from: http://www.kpmg.com/Global/en/IssuesAndInsights/Arti cles

6. Perkins S. International Reward and Recognition. Research Report, London: CIPD; 2006

7. PWC. Measuring the value of international assignments 2006 [cited 15 April 2019]. Available from https://www.pwc.fi/fi/palvelut/tiedostot/pwc_measuring_ the

8. Kandasivam A. MDEC announces record-high new investments of US\$3.67bil. Digital News Asia [newspaper on the Internet]. 2017 March 16 [cited 2019 Jan 31]. Available from: from

9. Frost and Sullivan (2018). Digital talent report 2017. 2018 [cited 15 April 2019]. Available from: (Online) Available from https://mdec.my/assets/pdf/DTR_2017.pdf

10. Megat Tajuddin MZ, Ibrahim, I. ICT to shape country's future. New Straits Times [newspaper on the Internet] 2017 Oct 16 [cited 2019 Jan 31]. Available from https://www.nst.com.my/opinion/letters/2017/10/291633/ ict-shape-

11. Mercer. Cultural Awareness Eases Expatriate Assignments. 2013 [cited 15 April 2019]. Available from http://mthink.mercer.com/cultural-awareness-eases

12. Bhaskar-Shrinivas P, Harrison DA, Shaffer MA, Luk DM. Input-based and time-based models of international adjustment: Meta-analytic evidence and theoretical mixed method studies will add to the richness of data Available from: tps://www.pwc.com/gx/en/managinghttps://www.digitalnewsasia.com/digital-economy/mdec-

extensions. Academy of management Journal. 2005 Apr $1 ; 48(2): 257-81$.

13. Kraimer ML, Wayne SJ, Jaworski RA. Sources of support and expatriate performance: The mediating role of expatriate adjustment. Personnel Psychology. 2001 Mar;54(1):71-99.

14. Awais Bhatti M, Mohamed Battour M, Rageh Ismail A. Expatriates adjustment and job performance: an examination of individual and organizational factors. International Journal of Productivity and Performance Management. 2013 Sep 13;62(7):694-717.

15. Gabel-Shemueli R, Dolan S. Do emotions matter? The role of emotional intelligence competences in crosscultural adjustment for international assignment. Management Research: Journal of the Iberoamerican Academy of Management. 2011 Nov 15;9(3):207-29.

16. Caligiuri P, Lazarova M. A model for the influence of social interaction and social support on female expatriates' cross-cultural adjustment. International Journal of Human Resource Management. 2002 Jan 1;13(5):761-72.

17. Earley PC, Ang S. Cultural intelligence: Individual interactions across cultures. Palo Alto: Stanford University Press; 2003.

18. Rosenbusch K, Cseh M. The cross-cultural adjustment process of expatriate families in a multinational organization: A family system theory perspective. Human Resource Development International. 2012 Feb 1;15(1):61-77.

19. Black JS. Work role transitions: A study of American expatriate managers in Japan. Journal of international business studies. 1988 Jun 1;19(2):277-94.

20. Lysgaard S. Adjustment in a foreign society: Norwegian Fulbright grantees visiting the United States. International Social Science Bulletin, 7, 45-51. Journal of Counseling Psychology. 1955;53(1):126-31.

21. Hofstede G. Dimensionalizing cultures: The Hofstede model in context. Online readings in psychology and culture. 2011;2(1):8.

22. Black JS, Mendenhall M, Oddou G. Toward a comprehensive model of international adjustment: An integration of multiple theoretical perspectives. Academy of management review. 1991 Apr 1;16(2):291-317

23. Black JS, Stephens GK. The influence of the spouse on American expatriate adjustment and intent to stay in Pacific Rim overseas assignments. Journal of management. 1989 Dec;15(4):529-44.

24. Haslberger A, Brewster C, Hippler T. The dimensions of expatriate adjustment. Human Resource Management. 2013 May;52(3):333-51.

25. Constantine MG, Okazaki S, Utsey SO. Selfconcealment, social self-efficacy, acculturative stress, and depression in African, Asian, and Latin American international college students. American Journal of orthopsychiatry. $2004 \mathrm{Jul} ; 74(3): 230-41$.

26. Okpara JO. Cross-cultural adjustment of expatriates: Exploring factors influencing adjustment of expatriates in Nigeria. International Journal of Cross Cultural Management. 2016 Dec;16(3):259-80.

27. Davies, S., Kraeh, A., and Froese, F. (2015). Burden or support? The influence of partner nationality on expatriate cross-cultural adjustment. Journal of Global Mobility, 3(2), pp.169-182,

28. Zhang LE, Peltokorpi V. Multifaceted effects of host country language proficiency in expatriate cross-cultural adjustments: aqualitative study in China. The International Journal of Human Resource Management. 
2016 Jul 19;27(13):1448-69.

29. Salgado JF, Bastida M. Predicting expatriate effectiveness: The role of personality, cross-cultural adjustment, and organizational support. International Journal of Selection and Assessment. 2017 Sep;25(3):267-75.

30. Harari MB, Reaves AC, Beane DA, Laginess AJ, Viswesvaran C. Personality and expatriate adjustment: A meta-analysis. Journal of Occupational and Organizational Psychology. 2018 Sep;91(3):486-517.

31. Wechtler H, Koveshnikov A, Dejoux C. Just like a fine wine? Age, emotional intelligence, and cross-cultural adjustment. International Business Review. 2015 Jun 1;24(3):409-18.

32. Cherniss C, Roche C, Barbarasch, B. Emotional Intelligence. In Encyclopedia of Mental Health: Second Edition; 2015. p. 108-115.

33. Mayer JD, Roberts RD, Barsade SG. Human abilities: Emotional intelligence. Annu. Rev. Psychol. 2008 Jan 10; 59:507-36.

34. Goleman D. What makes a great leader? Harvard Business Review Nov/Dec. 1998 Nov.

35. Bar-On R. The Bar-On model of emotional-social intelligence (ESI). Psicothema. 2006;18.

36. Mayer JD, Salovey, P, Caruso, D. Models of Emotional Intelligence. In Handbook of Intelligence. Cambridge University Press; 2012. p. 396-420.

37. Stein SJ, Book HE. The EQ edge: Emotional intelligence and your success. John Wiley \& Sons; 2011 Apr 5.

38. Palmer B, Walls M, Burgess Z, Stough C. Emotional intelligence and effective leadership. Leadership \& Organization Development Journal. 2001 Feb 1;22(1):510 .

39. Cote S, Miners CT. Emotional intelligence, cognitive Science Quarterly. 2006 Mar;51(1):1-28.

40. Côté S. Emotional Intelligence in Organizations. Annual Review of Organizational Psychology \& Organizational Behavior 2014 Mar 24; 1(1): 459-488, 2014

41. Zeidner M, Matthews G, Roberts RD. What we know about emotional intelligence: How it affects learning, work, relationships, and our mental health. MIT press; 2012 Feb 10.

42. Petrides KV, Furnham A. On the dimensional structure of emotional intelligence. Personality and individual differences. 2000 Aug 1;29(2):313-20.

43. Peltokorpi V. Cross-cultural adjustment of expatriates in Japan. The International Journal of Human Resource

44. Moon T. Emotional intelligence correlates of the fourfactor model of cultural intelligence. Journal of Managerial Psychology. 2010 Nov 9;25(8):876-98.

45. Shmueli Gabel R, Dolan SL, Luc Cerdin J. Emotional intelligence as predictor of cultural adjustment for success in global assignments. Career development international. 2005 Aug 1;10(5):375-95.

46. Koveshnikov, A., Wechtler, H., \& Dejoux, C. (2014). Cross-cultural adjustment of expatriates: The role of emotional intelligence and gender. Journal of World Business, 49(3), 362-371.

47. Beheshtifar M, Norozy T. Social skills: A factor to employees' success. International Journal of Academic Research in Business and social sciences. 2013 Mar 1;3(3):74.

48. Mallinckrodt B. Attachment, social competencies, social support, and interpersonal process in psychotherapy. Psychotherapy research. 2000 Sep 1;10(3):239-66.

49. Recommendation of the European parliament and of the councilof 18 December 2006 on key competences for intelligence, and job performance. Administrative Management. 2008 Sep 1;19(9):1588-606. lifelong learning (2006/962/EC). 2006. [cited 15 April

2019]. Available from https://eurlex.europa.eu/LexUriServ/LexUriServ.do?uri=

50. Bierman KL. Peer rejection: Developmental processes and intervention strategies. New York:Guilford Press; 2004.

51. Kostelnik MJ, Whiren AP, Soderman AK, Stein LC, Gregory K. Guiding children's social development: Theory to practice (4th ed.) New York; Cengage Learning; 2002

52. Hechanova R, Beehr TA, Christiansen ND. Antecedents and consequences of employees' adjustment to overseas assignment: a meta-analytic review. Applied psychology. 2003 Apr;52(2):213-36.

53. Mol ST, Born MP, Willemsen ME, Van Der Molen HT Predicting expatriate job performance for selection purposes: A quantitative review. Journal of CrossCultural Psychology. 2005 Sep;36(5):590-620.

54. Abe H, Wiseman RL. A cross-cultural confirmation of the dimensions of intercultural effectiveness. International Journal of Intercultural Relations. 1983 Jan 1;7(1):53-67.

55. Wang D, Fan D, Freeman S, Zhu CJ. Exploring crosscultural skills for expatriate managers from Chinese multinationals: Congruence and contextualization. Asia Pacific Journal of Management. 2017 Mar 1;34(1):12346.

56. Mendenhall M, Oddou G. The dimensions of expatriate acculturation: A review. Academy of management review. 1985 Jan 1;10(1):39-47.

57. Lee LY, Kartika N. The influence of individual, family, and social capital factors on expatriate adjustment and performance: The moderating effect of psychology contract and organizational support. Expert Systems with Applications. 2014 Sep 1;41(11):5483-94

58. Deci EL, Ryan RM. Self-determination theory: A macrotheory of human motivation, development, and health. Canadian psychology/Psychologie canadienne. 2008 Aug;49(3):182.

59. Porter LW. and Lawler EE. (1968). What Job Attitudes Can Tell Us About Employee Motivation, Harvard Business Review. 1968; 46(1): 118-126

60. Haines III VY, Saba T, Choquette E. Intrinsic motivation for an international assignment. International Journal of Manpower. 2008 Aug 15;29(5):443-61.

61. Ang S, Van Dyne L, Koh C, Ng KY, Templer KJ, Tay C, Chandrasekar NA. Cultural intelligence: Its measurement and effects on cultural judgment and decision making, cultural adaptation and task performance. Management and organization review. 2007 Nov;3(3):335-71.

62. Chen G, Kirkman BL, Kim K, Farh CI, Tangirala S. When does cross-cultural motivation enhances expatriate effectiveness? A multilevel investigation of the moderating roles of subsidiary support and cultural distance. Academy of Management journal. 2010 Oct;53(5):1110-30.

63. Ramalu S, Wei CC, Raduan CR. Expatriate Performance in International Assignments: The Role of Cultural Intelligence as Dynamic Intercultural Competency. International Journal of Business and Social Science. 2011; 2(9): 59-71.

64. Froese FJ. Motivation and adjustment of self-initiated expatriates: The case of expatriate academics in South Korea. The International Journal of Human Resource Management. 2012 Mar 1;23(6):1095-112.

65. Bandura A, Schunk DH. Cultivating competence, selfefficacy, and intrinsic interest through proximal selfmotivation. Journal of personality and social psychology. 
1981 Sep;41(3):586.

66. Levitats Z, Vigoda-Gadot E. Yours emotionally: How emotional intelligence infuses public service motivation and affects the job outcomes of public personnel. Public Administration. 2017 Sep;95(3):759-75.

67. Velten JC. Intercultural Communication Readiness Assessment and Competency-Based Preparation: A Trend Analysis of Latin American Expatriate Missions. Texas Speech Communication Journal. 2015 Sep 1;39(1).

68. Evelyne N, Muathe S, Kilika J. Mediating Effect of Motivation on Employees Performance in Private Equity Firms, Kenya. Journal of Human Resource Management. 2018 Sep 21;6(2):78-84.

69. Charbonneau D, Barling J, Kelloway EK. Transformational leadership and sports performance: The mediating role of intrinsic motivation 1 . Journal of applied social psychology. $2001 \mathrm{Jul} ; 31(7): 1521-34$.

70. Ramalu SS, Rose RC, Uli J, Kumar N. Personality and cross-cultural adjustment among expatriate assignees in Malaysia. International Business Research. 2010 Oct 1;3(4):96-104.

71. Saunders M. Lewis P. Thornhill A. Research Methods for Business Students. Essex: Pearson; 2012

72. Kothari CR. Research Methodology Methods \& Techniques. Second Edition, New Delhi: New Age International Publisher; 2004

73. Krejcie RV, Morgan DW. Determining sample size for research activities. Educational and psychological measurement. 1970 Sep;30(3):607-10.

74. Tabachnick BG, Fidell LS, Ullman JB. Using multivariate statistics. Boston, MA: Pearson; 2007 Mar 3.

75. Searle W, Ward C. The prediction of psychological and sociocultural adjustment during cross-cultural transitions. International journal of intercultural relations. 1990 Jan $1 ; 14(4): 449-64$

76. Wong CS, Law KS. The effects of leader and follower emotional intelligence on performance and attitude: An exploratory study. The leadership quarterly. 2002 Jun $1 ; 13(3): 243-74$

77. Holopainen J, Björkman I. The personal characteristics of the successful expatriate: A critical review of the literature and an empirical investigation. Personnel review. 2005 Feb 1;34(1):37-50.

Liu X, Shaffer MA. An investigation of expatriate adjustment and performance: A social capital perspective. International Journal of Cross Cultural Management. 2005 Dec;5(3):235-54.

78. Liu CH, Lee HW. A proposed model of expatriates in multinational corporations. Cross Cultural Management: An International Journal. 2008 May 2;15(2):176-93.

79. Rioux SM, Bernthal PR, Wellins RS. The globalization of human resource practices survey report. HR Benchmark group. 2000 Jun;1(3):1-22.

80. Sangoseni O, Hellman M, Hill C. Development and validation of a questionnaire to assess the effect of online learning on behaviors, attitude and clinical practices of physical therapists in United States regarding of evidence-based practice. Internet $\mathrm{J}$ Allied Health Sci Pract 2013; 11:1-12.

81. Hair JF, Ringle CM, Sarstedt M. PLS-SEM: Indeed, a silver bullet. Journal of Marketing theory and Practice. 2011 Apr 1;19(2):139-52.

82. Hair JF, Black WC, Babin JB, Anderson RE, Tatham RL. Multivariate Data Analysis, (Sixth Edition). Upper Saddle River, New Jersey, U.S.A: Pearson Prentice-Hall International; 2010

83. Garson D. Partial least squares (PLS-SEM). Asheboro, NC: Statistical Publishing. 2016

\section{AUTHORS PROFILE}

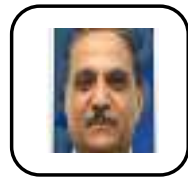

Jugindar Singh Kartar Singh is a Senior Lecturer attached to Asia Pacific University (APU) and has 5 years of teaching and training experience. He has vast industrial experience and held leadership positions in large Banks in Malaysia. With a postgraduate in Business Administration, he has written articles and presented several papers in international and national conferences.

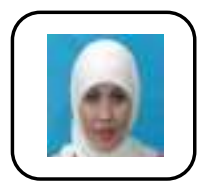

Nik Hasnaa Nik Mahmood is an Associate Professor/ Head of Department attached to the Human Resource Development Department, UTM RAZAK School of Engineering and Advanced Technology, Universiti Teknologi Malaysia, International Campus. She has written and published several papers in renowned journals and presented papers at local and international conferences.

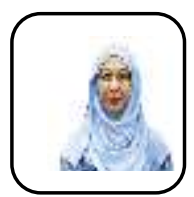

Zabedah bt Othman obtained her Phd in 2017. She specializes in Human Resource Management. She held various leadership positions in Human Resource management before becoming an academician. Currently she is a lecturer in Open University Malaysia. 